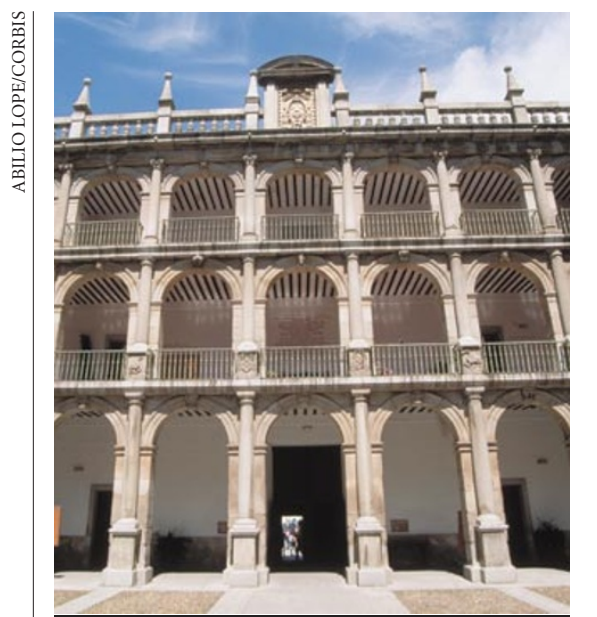

Building for the future: the new report suggests major changes for university tenure.

Research, Development and Technological Innovation (see Nature 400, 393; 1999). It proposes in particular that there should be increased support for basic research and that links between universities and industry should be boosted.

In order to increase human resources in research and development, it says that a new permanent post of research professor should be created. The occupant of such a post would be employed directly by the universities and would address the research needs of a particular department as well as carry out $\mathrm{PhD}$ teaching activities.

A revised version of the report is likely to be presented to the Parliament in September, after comments received during a period of consultation have been taken into account.

The move no doubt reflects the high dissatisfaction level expressed by researchers and professors at Spanish universities. Such concerns appear to be sorted out, at least in part, in the CRUE report.

Raul Villar, rector of the Autonomous University of Madrid, says that the report should be considered as a consultation document which is now open to comment from academics and other social groups.

He points out that, although other countries may have adopted different recruitment procedures, those that are proposed in the report seem the most appropriate for Spain, as the report respects the independence of universities from the government.

"The report has to be strongly taken into account," says Juan Carlos GuerraZunzunegui, the parliamentary spokesman on education for the ruling Popular Party. He adds that he is keen to encourage a broad debate on university recruitment.

Xavier Bosch

\title{
Modified reforms end two years of deadlock at CNRS
}

Paris

Amid talk last week of the imminent dismissal of France's controversial research minister, Claude Allègre (see page 430), some of his suggested reforms for the Centre National de la Recherche Scientifique (CNRS) were given provisional approval after two years of deadlock.

The reforms give the CNRS, Europe's largest public research agency, an internal administrative overhaul that has been backed by virtually everyone at CNRS. This includes the scientific unions that were bitterly opposed to Allègre when he tabled his initial reform proposals in 1998.

The most important changes approved by the agency's administrative council last week were welcomed by many scientists as bringing more flexibility and independence. These reforms include trimming the size of the scientific council - which defines the agency's scientific blueprint - and opening it to foreign members. The council will be elected internally, its members will be named, and it will choose its own president.

Another major change involves redefining the role of the president of CNRS, who will act as strategic director of the establishment and be responsible for relations with the government and universities. The director general will oversee the day-to-day running of the institution. The CNRS will also have an external evaluation committee made up of French and foreign scientists.

While incorporating some of Allègre's original suggestions, the reforms have been stripped of the most controversial elements, such as reducing the influence of the National Committee for Scientific Research. This body acts as the 'parliament' of the country's scientists, and is involved in evaluating laboratories and administering recruitment. Allègre also stepped back from handing responsibility for much of the work carried out in CNRS laboratories to the universities.

Researchers have long criticized the CNRS for being too rigid. "It's a very important loosening up of the system," says HenriEdouard Audier, a chemist at the École Polytechnique near Paris and a member of the board of a researchers' trade union, the Syndicat National des Chercheurs Scientifiques.

Audier believes the most important lesson to emerge from the two-year debate is that, once the CNRS had been given increased independence from the government, it had been able to agree on its own reforms without excessive government interference. "When there is consultation, the CNRS can modernize itself," says Audier. Heather McCabe

\section{Giant tortoises come home}

\section{London}

The one-thousandth giant tortoise (Geochelone elephantopus hoodensis) to be repatriated to its native Galapagos island of Española was released last week. This is a milestone in a breeding programme begun in 1963 to save a rare tortoise threatened by humans and human-introduced species.

Several centuries of exploitation had left a reduced and dispersed population that was not reproducing. The G. e. hoodensis project began with only 14 tortoises - all that could be found at the time. After being bred in captivity, the tortoises are reintroduced into their natural habitat (see right).

The project is led by the Charles Darwin Research Station on the Galapagos island of Santa Cruz, in conjunction with the Galapagos National Park. The research station now faces the challenge of dealing with many other threatened tortoise species. Officials says it will have succeeded when "humans are no longer needed to lead the tortoises of Española or other islands back home".

Natasha Loder

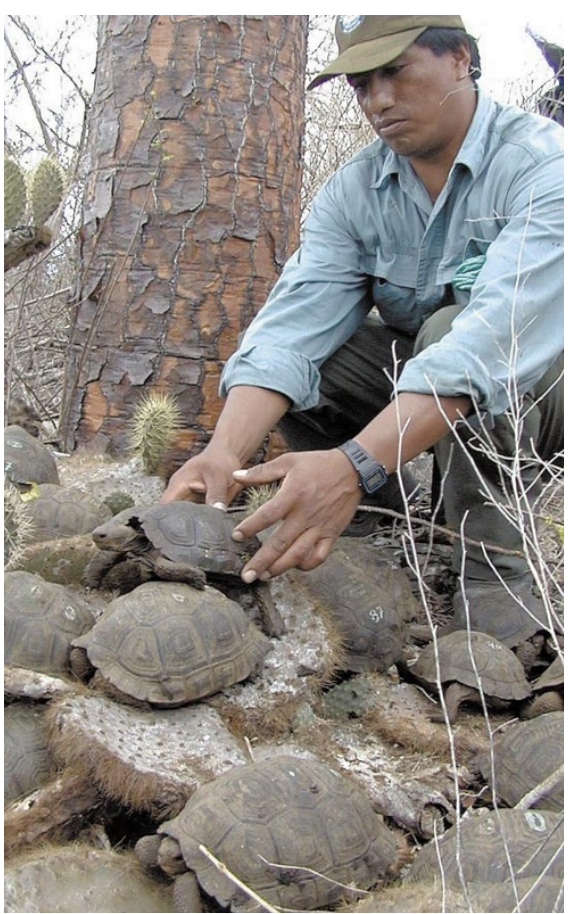

